\title{
Title: Coprecipitation of Arsenate with Metal Oxides: Nature, Mineralogy and Reactivity of Aluminum Precipitates
}

\author{
List of authors: \\ Prof. Antonio Violante \\ Dipartimento di Scienze del Suolo, della Pianta e dell'Ambiente \\ Università di Napoli Federico II \\ Via Università 100, Portici, Napoli \\ ITALY \\ Phone: $+39-0812539176$ \\ Fax: +39-0812539186 \\ E-mail: violante@unina.it \\ Dr. Mariarosaria Ricciardella \\ Dipartimento di Scienze del Suolo, della Pianta e dell'Ambiente \\ Università di Napoli Federico II \\ Via Università 100, Portici, Napoli \\ ITALY \\ Phone: +39-0812539168 \\ Fax: +39-0812539186 \\ E-mail: mricciar@unina.it \\ Dr. Del Gaudio Stefania \\ Dipartimento di Scienze del Suolo, della Pianta e dell'Ambiente \\ Università di Napoli Federico II \\ Via Università 100, Portici, Napoli \\ ITALY \\ Phone: $+39-0812539168$ \\ Fax: $+39-0812539186$ \\ E-mail: sdelgaud@unina.it \\ Dr. Pigna Massimo \\ Dipartimento di Scienze del Suolo, della Pianta e dell'Ambiente \\ Università di Napoli Federico II \\ Via Università 100, Portici, Napoli \\ ITALY \\ Phone: +39-0812539168 \\ Fax: +39-0812539186 \\ E-mail: massimo.pigna@unina.it \\ Pages 5 \\ Table 1 \\ Figures 3
}


Table S1. Positions of the $v$ (As-O) bands in the IR spectra of Al-As coprecipitates formed at an initial As/Al (R) molar ratio of 0.1

$\begin{array}{cccc}\text { Sample } & \mathrm{pH} & 30 \mathrm{~d} & 710 \mathrm{~d} \\ \text { 4R0.1 } & 4.0 & 864 \mathrm{~cm}^{-1} & 864 \mathrm{~cm}^{-1} \\ \text { 7R0.1 } & 7.0 & 859 \mathrm{~cm}^{-1} & 850 \mathrm{~cm}^{-1} \\ \text { 10R0.1 } & 10.0 & 850 \mathrm{~cm}^{-1} & 843 \mathrm{~cm}^{-1}\end{array}$


Figure S1
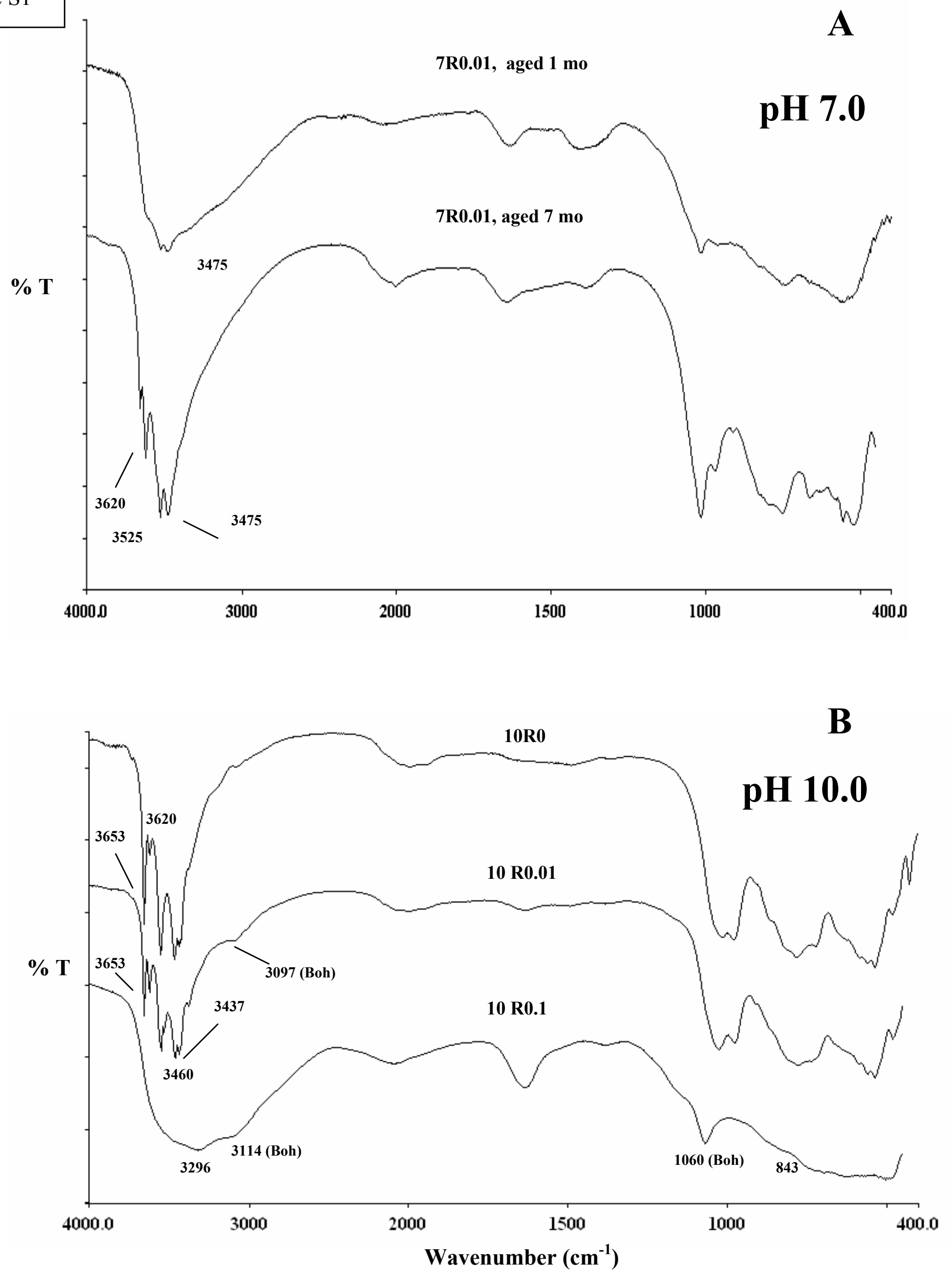

Figure S1. Infrared spectra of selected samples formed at $\mathrm{pH} 7.0$ and 10.0 after $30 \mathrm{~d}$ or $210 \mathrm{~d}$ of aging at $50^{\circ} \mathrm{C}$. (for sample symbols see Table 1 ). 
Figure S2

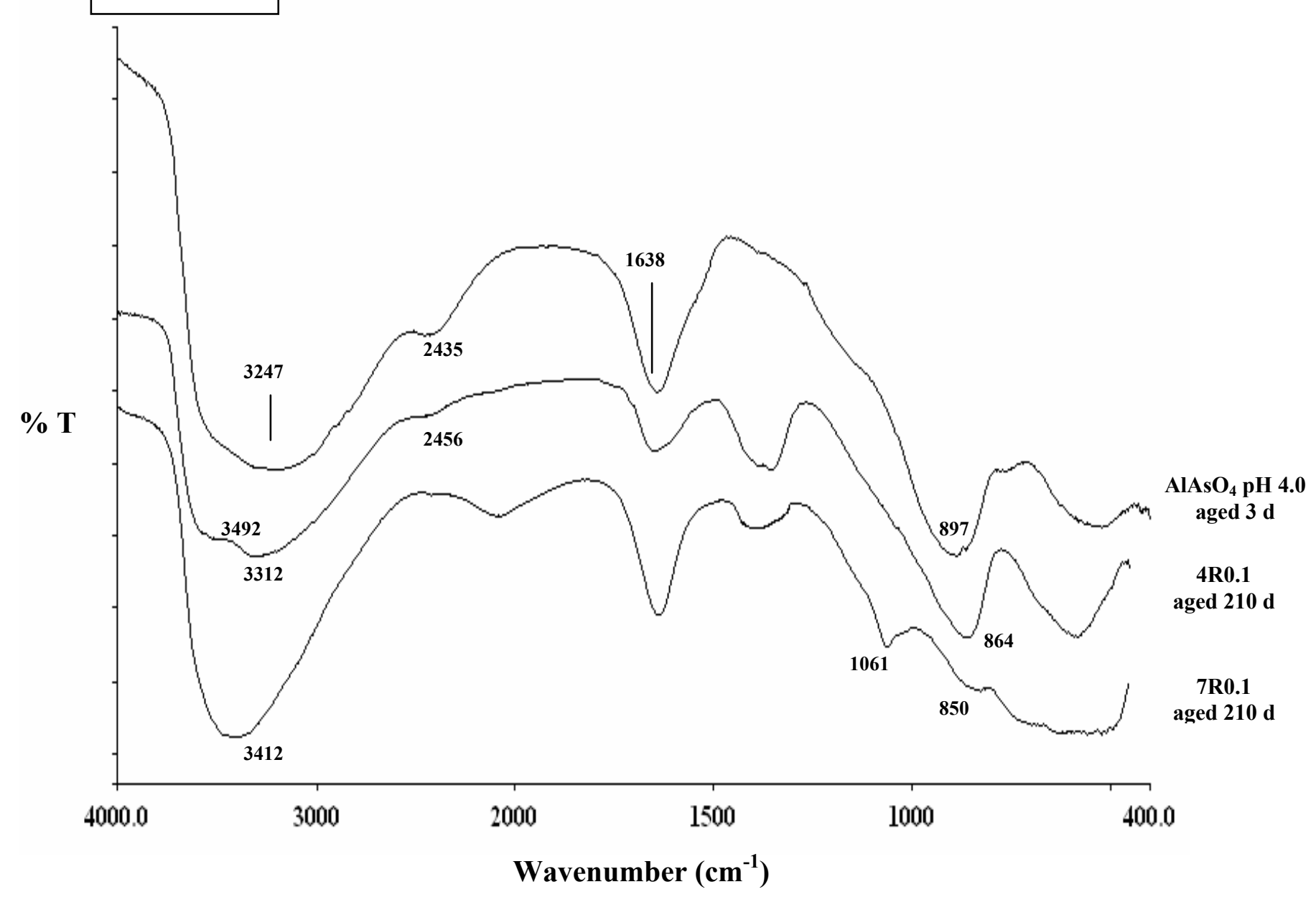

Figure S2. Infrared spectra of an aluminum arsenate precipitate formed at $\mathrm{pH} 4.0$ and aged $3 \mathrm{~d}$ at $50^{\circ} \mathrm{C}$ and of the samples $4 \mathrm{R} 0.1$ and $7 \mathrm{R} 0.1$ aged $210 \mathrm{~d}$ at $50^{\circ} \mathrm{C}$. The band at $1061 \mathrm{~cm}^{-1}(7 \mathrm{R} 0.1)$ is characteristic of poorly crystalline boehmite. 
Figure S3

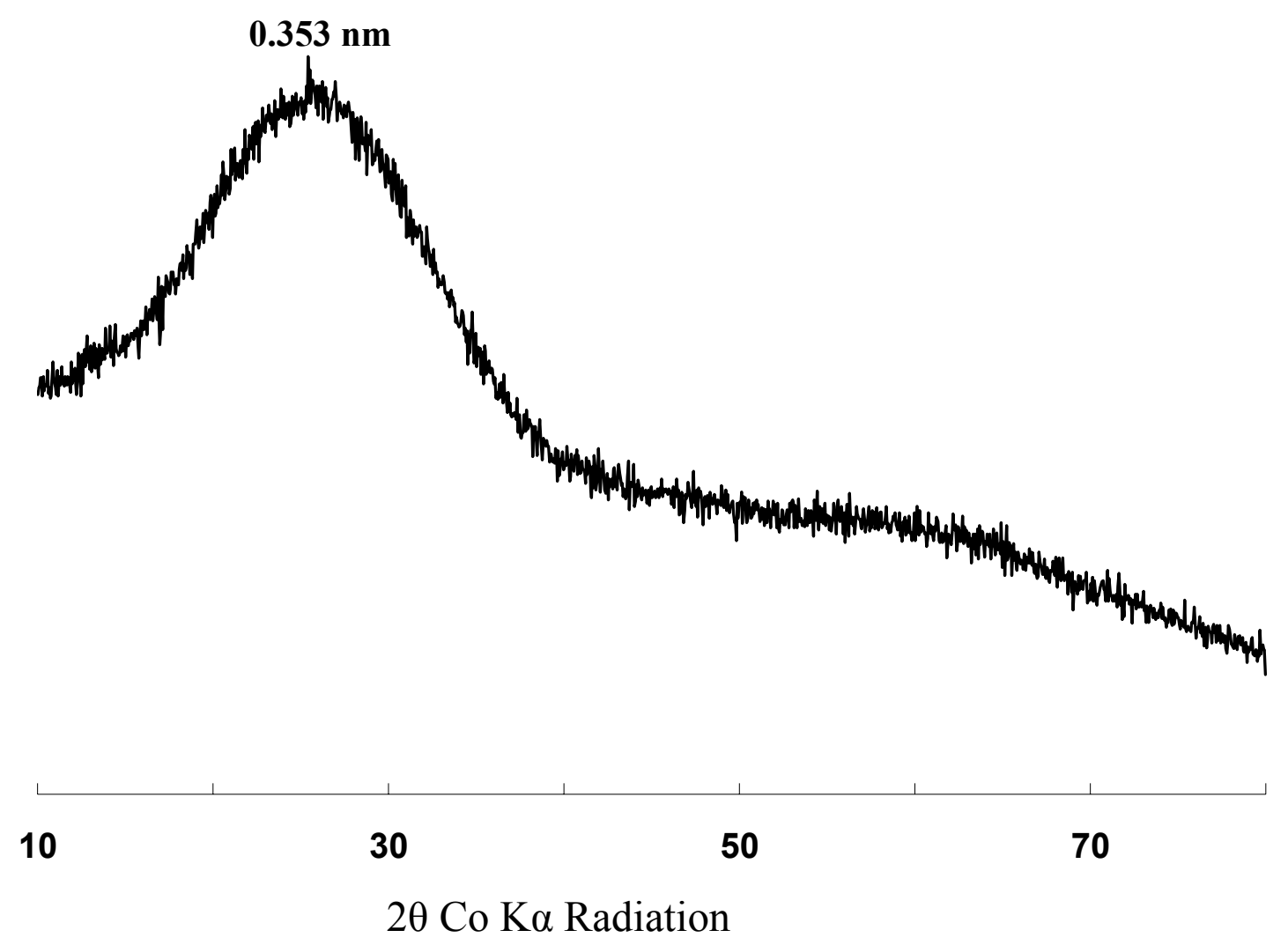

Figure S3. X-ray powder diffractogram of a randomly oriented aluminum arsenate precipitate formed at $\mathrm{pH} 4.0$ and aged $3 \mathrm{~d}$ at $50^{\circ} \mathrm{C}$. 